\title{
O REGIME DE COOPERAÇÃO FEDERATIVA DA POLÍTICA EDUCACIONAL uma análise a partir dos efeitos redistributivos do FUNDEF e do FUNDEB
}

\author{
Flávia Alves da Silva ${ }^{1}$ \\ Jeanne Michelle Matozinhos de Carvalho Ferreira ${ }^{2}$ \\ Geraldo Eustáquio Moreira ${ }^{3}$
}

\begin{abstract}
Resumo: O propósito deste artigo é analisar o regime de cooperação federativa da política educacional, em especial, o financiamento da educação básica no Brasil, sobretudo, os efeitos redistributivos do FUNDEF e FUNDEB, as inovações trazidas por esses fundos, suas limitações enquanto instrumento capaz de redução das desigualdades regionais do sistema educacional brasileiro, bem como identificar os principais desafios enfrentados pelos entes federados ao gerenciarem esses fundos. Desde a aprovação do Fundo de Manutenção e Desenvolvimento do ensino fundamental e de Valorização do Magistério (FUNDEF), criado em 1996, têm-se discutido ganhos, problemas e necessidades de modificações do respectivo fundo. Sendo assim, a alteração ou continuidade do FUNDEF precisou de uma nova Emenda Constitucional, uma vez que o referido fundo foi aprovado para um período de 10 anos, compreendendo os anos de 1997 a 2006. Surgiu então, o Fundo de Manutenção e Desenvolvimento da Educação Básica (FUNDEB) que ampliou a vinculação das receitas dos impostos e transferências dos estados e municípios para o ensino fundamental de $15 \%$ para $20 \%$, bem como a possibilidade de utilização destes recursos em toda a educação básica. Com base na revisão de literatura empreendida, discute-se desde o contexto sócio-histórico do financiamento da educação básica no Brasil até as principais propostas de melhorias dos problemas enfrentados pelos entes federados ao gerenciarem esses fundos.
\end{abstract}

Palavras-chave: Regime de cooperação. Entes Federados. FUNDEF. FUNDEB. Educação Básica.

\section{EL RÉGIMEN DE COOPERACIÓN FEDERATIVA DE LA POLÍTICA EDUCACIONAL un análisis a partir de los efectos redistributivos del FUNDEF y del FUNDEB}

Resumen: El propósito de este artículo es analizar el régimen de cooperación federativa de la política educativa, en especial, el financiamiento de la educación básica en Brasil, sobre todo, los efectos redistributivos del FUNDEF y FUNDEB, las innovaciones traídas por esos fondos, sus limitaciones como instrumento capaz de reducción De las desigualdades regionales del sistema educativo brasileño, así como identificar los principales desafíos enfrentados por los entes federados al gestionar esos fondos. Desde la aprobación del Fondo de Mantenimiento y

\footnotetext{
${ }^{1}$ Mestranda em Gestão Pública pela UnB. Pós-Graduada em Gestão e Orientação Educacional. Atua como Pedagoga na Diretoria de Desenvolvimento Social da Universidade de Brasília - UnB. E-mail: flavia.silva@gmail.com

${ }^{2}$ Mestranda em Gestão Pública pela UnB. Advogada e Pós-Graduada em Direito Administrativo. Atua como Assistente Social na Universidade de Brasília - UnB. E-mail: jeanne.ferreira@unb.br

3 Doutor em Educação Matemática pela PUCSP. Mestre em Educação pela UCB. Docente da Universidade de Brasília - UnB. Pesquisador do Programa de Pós-Graduação Stricto Sensu em Educação - PPGE/UnB (Mestrado e Doutorado). E-mail: geust2007@gmail.com
} 


\title{
REVISTA ELETRÔNICA \\ DA GRADUAÇÃO/PÓS-GRADUAÇÃO EM EDUCAÇÃO UFG/REJ
}

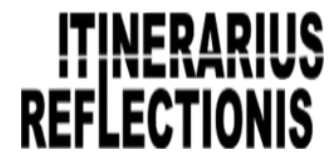

ISSN. 1807-9342

Volume 14, N. 2, 2018

Desarrollo de la Enseñanza Fundamental y de Valorización del Magisterio (FUNDEF), creado en 1996, se han discutido las ganancias, problemas y necesidades de modificaciones del fondo. Por lo tanto, la modificación o continuidad del FUNDEF necesitó una nueva Enmienda Constitucional, ya que dicho fondo fue aprobado para un período de 10 años, comprendiendo los años 1997 a 2006. Surgió entonces, el Fondo de Mantenimiento y Desarrollo de la Educación (FUNDEB) que amplió la vinculación de los ingresos de los impuestos y transferencias de los estados y municipios a la enseñanza fundamental del $15 \%$ al $20 \%$, así como la posibilidad de utilización de estos recursos en toda la educación básica. Con base en la revisión de literatura emprendida, se discute desde el contexto socio-histórico del financiamiento de la educación básica en Brasil hasta las principales propuestas de mejoras de los problemas enfrentados por los entes federados al gestionar esos fondos.

Palabras-clave: Régimen de cooperación. Entidades Federados. FUNDEF. FUNDEB. Educación Básica.

\section{THE EDUCATIONAL POLICY FEDERATIVE COOPERATION REGIME an analysis from the redistributive effects of FUNDEF and FUNDEB}

\begin{abstract}
The purpose of this article is to analyze the federative cooperation regime of educational policy, especially the financing of basic education in Brazil, especially FUNDEF and FUNDEB, its positive and negative aspects, as well as to identify the main challenges faced by the federated entities Manage these funds. Since the approval of the Fund for Maintenance and Development of Elementary Education and Valorization of Teaching (FUNDEF), created in 1996, there have been discussions about gains, problems and needs for changes in the respective fund. Therefore, the alteration or continuity of FUNDEF necessitated a new Constitutional Amendment, since the said fund was approved for a period of 10 years, covering the years 1997 to 2006. The Fund for Maintenance and Development of Education (FUNDEB), which increased the linkage of tax revenues and transfers from states and municipalities to basic education from $15 \%$ to $20 \%$, as well as the possibility of using these resources in all basic education. Based on the literature review undertaken, it is discussed from the socio-historical context of the financing of basic education in Brazil to the main proposals for improvement of the problems faced by the federated entities in managing them.
\end{abstract}

Keywords: Cooperation regime. Federated Entities. FUNDEF. FUNDEB. Basic Education.

\section{IDEIAS INTRODUTÓRIAS}

No Brasil, a organização federativa e a repartição de competências entre níveis de governo têm expressão específica no setor educacional. São elementos essenciais dessa especificidade o reconhecimento da autonomia dos sistemas federal, estaduais e municipais de ensino, a orientação de uma organização em regime de colaboração entre esses sistemas e a definição de papéis e prioridades de atuação das esferas de governo na educação.

A responsabilidade pela oferta de educação escolar é compartilhada pelos três níveis governamentais, sendo: atuação prioritária dos municípios no ensino fundamental e educação infantil e dos estados no ensino fundamental e no ensino médio; para a 


\section{REVISTA ELETRÔNICA \\ DA GRADUAÇÃO/PÓS-GRADUAÇÃO EM EDUCAÇÃO UFG/REJ}

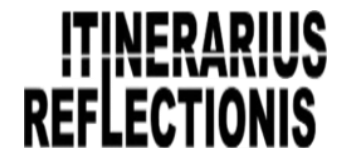

ISSN. 1807-9342

Volume 14, N. 2, 2018

União, a organização e o financiamento da rede pública federal de ensino e a prestação de assistência financeira e técnica aos estados e municípios, buscando garantir equalização de oportunidades e padrão mínimo de qualidade de ensino.

A Lei de Diretrizes e Bases da Educação (Lei No 9.394 de 1996) afirma que a União aplicará, anualmente, nunca menos de dezoito, e os Estados, o Distrito Federal e os Municípios, vinte e cinco por cento, ou o que consta nas respectivas Constituições ou Leis Orgânicas, da receita resultante de impostos, compreendidas as transferências constitucionais, na manutenção e desenvolvimento do ensino público (BRASIL, 1996).

Desde a promulgação da Constituição Federalde1988 tem ocorrido no Brasil uma grande descentralização de recursos fiscais da União para estados e municípios. Um dos principais instrumentos dessa descentralização foi a vinculação de parte dos recursos transferidos aos estados e municípios, com destaque para o ensino fundamental. Nesse sentido, a criação do Fundo de Manutenção e Desenvolvimento do Ensino Fundamental e de Valorização do Magistério (FUNDEF) representou não só a vinculação de transferências como também a de receitas próprias dos governos subnacionais para o gasto com educação pública com destaque para o ensino fundamental (MENDES, 2001).

O Fundo de Manutenção e Desenvolvimento do Ensino Fundamental e de Valorização do Magistério (FUNDEF) é mais uma entre as políticas públicas para modernizar a educação no país, em longo prazo. Estipulando padrões de financiamento para o sistema educacional, essa legislação garante a manutenção dos recursos para o segmento, além de primar pela diminuição das desigualdades regionais, tão presentes no setor (CAMPOS e SOBREIRA, 2008).

Vazques (2005, p. 149) destaca que:

Segundo o então Ministro da Educação Paulo Renato Souza (1998), o FUNDEF é um exemplo inovador de política social que visa aos seguintes objetivos estratégicos: promover a justiça social; promover uma política nacional de equidade; promover a efetiva descentralização e promover a melhoria da qualidade da educação e a valorização do magistério.

No Balanço do primeiro ano do FUNDEF, Souza (1998) entende que a promoção de uma política nacional de equidade significa que os recursos vinculados ao ensino obrigatório são redistribuídos entre cada Estado e seus Municípios de acordo 


\section{REVISTA ELETRÔNICA \\ DA GRADUAÇÃO/PÓS-GRADUAÇÃO EM EDUCAÇÃO UFG/REJ}

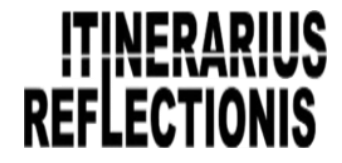

ISSN. 1807-9342

Volume 14, N. 2, 2018

com o número de alunos atendidos em suas redes, cabendo ao Governo Federal complementar o Fundo sempre que não for atingido o valor mínimo anual por aluno.

O Fundo de Manutenção e Desenvolvimento do Ensino Fundamental e de Valorização do Magistério (FUNDEF) precursor do atual FUNDEB financiou o ensino fundamental entre os anos de 1997 e 2006.

De acordo com o artigo $2^{\circ}, \S 1^{\circ}$, da Lei $n^{\circ} 9.424 / 96$, que dispõe sobre o FUNDEF, a distribuição dos recursos do fundo entre os governos estaduais e municipais, dar-se-á na proporção do número de alunos matriculados anualmente nas escolas cadastradas nas respectivas redes estaduais e municipais de ensino fundamental regular. Dessa forma, para cada aluno matriculado nesse nível de ensino, será repassado um valor médio do gasto aluno/ano igual dentro de cada estado. Esse valor é dado pela razão entre o total de recursos do FUNDEF estadual e o total do número de matrículas no ensino fundamental regular no estado (VAZQUEZ, 2005).

Segundo Rossinholi (2008), a alteração ou continuidade do FUNDEF precisava de nova Emenda Constitucional, uma vez que o mesmo foi aprovado para um período de 10 anos. Nesse sentido, várias Propostas de Emenda Constitucional - PECs foram apresentadas nesse período de 1997 a 2006, seja para modificações de critérios, criação de novos fundos, sendo um para cada nível de ensino: Educação Infantil, Ensino Médio e Superior, Fundo de Manutenção e Desenvolvimento da Educação Básica - FUNDEB, ou ainda aumento de recursos para o FUNDEF. Decorrido o período de vigência do FUNDEF, foi possível visualizar as principais discussões que ocorreram sobre seus critérios por meio das propostas apresentadas no Congresso Nacional brasileiro que culminaram na apresentação da PEC n 415/05 e aprovação do FUNDEB pela Emenda Constitucional - EC n 53 de 2006, regulamentado pela Medida Provisória - MP $\mathrm{n}^{\circ}$ 339/06 que foi transformada na Lei $n^{\circ}$ 11.494/07 (ROSSINHOLI, 2008).

Essa Emenda Constitucional que transformou o FUNDEF em FUNDEB ampliou a vinculação das receitas dos impostos e transferências dos estados e municípios para o ensino fundamental de $15 \%$ para $20 \%$, bem como a possibilidade de utilização destes recursos em toda a educação básica (e não apenas no ensino fundamental), ou seja, creche, pré-escola, ensino fundamental, ensino médio e educação de jovens e adultos. Ambos os fundos são transferências governamentais do tipo condicional obrigatória, ou seja, as regras sobre os montantes a serem transferidos aos governos subnacionais são 


\section{REVISTA ELETRÔNICA \\ DA GRADUAÇÃO/PÓS-GRADUAÇÃO EM EDUCAÇÃO \\ UFG/REJ}

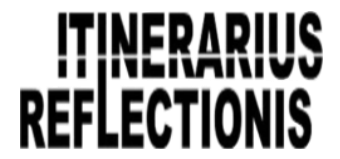

ISSN. 1807-9342

Volume 14, N. 2, 2018

definidas na Constituição da República e determinadas por lei e têm como finalidade incentivar a oferta de educação pelos entes federativos (AFONSO, SOARES e CASTRO, 2013). No que se refere à vinculação de percentual para pagamento dos profissionais do magistério, a Emenda Constitucional no 53/2006 mantém a vinculação de $60 \%$ para o pagamento dos profissionais do magistério da educação básica que estejam em efetivo exercício (BRASIL, 1988).

O FUNDEB que tem seu financiamento baseado nas três esferas de governo ampliou o número de categorias para diferenciação de valores mínimos per capita, nas quais incluiu patamares diferenciados para as crianças matriculadas em creches, na préescola, no ensino fundamental em tempo integral, médio urbano, médio rural, médio em tempo integral, médio integrado à educação profissional, em escolas voltadas para a educação indígena e quilombola e nos projetos de educação de jovens e adultos. Outro aspecto inovador associado ao FUNDEB é o estabelecimento de um índice de avaliação de resultados com vistas a balizar a avaliação de desempenho das unidades educacionais (MENDES, MIRANDA e COSIO, 2008).

O objetivo deste artigo, portanto, é analisar o regime de cooperação dos entes federados no tocante ao financiamento da Educação Básica no Brasil, identificando as inovações trazidas com a criação do FUNDEF e FUNDEB e as limitações desses fundos como instrumentos capazes de contribuir para a redução das desigualdades regionais no sistema educacional brasileiro. Passemos, então a expor o contexto sócio-histórico do financiamento da educação básica no Brasil.

\section{CONTEXTO SÓCIO-HISTÓRICO DO FINANCIAMENTO DA EDUCAÇÃO BÁSICA NO BRASIL}

A ação do Estado no período de 1995-2007 foi marcada por reestruturações da gestão da política educacional, sobretudo no campo do ensino fundamental e mais atualmente, da educação básica. Assistiu-se, também, à reformulação de programas existentes e à criação de novos programas e projetos/atividades. É importante salientar que a ação do governo federal no período introduziu novos mecanismos de gestão, definiu critérios técnicos na determinação alocativa dos recursos, induziu a descentralização institucional e financeira das ações e avançou nos mecanismos de 


\section{REVISTA ELETRÔNICA \\ DA GRADUAÇÃO/PÓS-GRADUAÇÃO EM EDUCAÇÃO UFG/REJ}

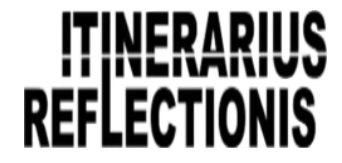

ISSN. 1807-9342

Volume 14, N. 2, 2018

avaliação dos sistemas de ensino. A estratégia unificadora por trás desses projetos e medidas buscou fortalecer o papel coordenador e articulador do governo federal na área da educação fundamental e na educação básica (CASTRO, 2010).

A desigualdade de renda presente entre as unidades da federação é um fato que exige mecanismos de transferência de recursos que promovam a redistribuição regional da renda, cujo propósito é repassar recursos fiscais de regiões mais desenvolvidas para as menos desenvolvidas. O objetivo principal é garantir que as unidades federativas com diferentes dimensões de bases tributárias utilizem esforços iguais no custeio de serviços públicos, em especial na Educação. Ou seja, um ente federativo que tenha menor capacidade de geração de recursos fiscais deve receber verbas proporcionais às suas necessidades (AFONSO, SOARES e CASTRO, 2013).

O marco legal da política educacional brasileira é representado pela Constituição Federal de 1988, pela Lei de Diretrizes e Bases da Educação Nacional (BRASIL, 1996b), pela Emenda Constitucional no 14/1996 (BRASIL, 1996a) e por um conjunto de normas infraconstitucionais e resoluções do Conselho Nacional de Educação. Esse arcabouço jurídico assegura a todos os brasileiros as condições formais para o exercício do direito básico à educação, especialmente o direito ao ensino fundamental, além de fixar a atual estrutura de responsabilidades e competências para a oferta de educação no Brasil (CASTRO, 2010).

A descentralização da gestão dos recursos destinados à educação remete aos anos 1980, num primeiro momento com a Emenda Calmon, que significou um esforço de vinculação de determinados impostos aos gastos educacionais. Mais tarde, com a promulgação da Constituição de 1988, tal processo tornou-se mais nítido, reflexo da democratização, que exigia uma maior autonomia de entes subnacionais na gestão dos recursos governamentais (CAMPOS e SOBREIRA, 2008).

A criação do FUNDEF na década de 1990 revelou, assim, uma consolidação das tendências à descentralização do gerenciamento da educação. Por trás dessa proposta subentendeu-se o intuito de imprimir uma maior visibilidade na gestão orçamentária e financeira dos recursos destinados ao ensino fundamental, conclamando, também, um maior envolvimento dos cidadãos no acompanhamento das questões concernentes ao fundo (CAMPOS e SOBREIRA, 2008). 


\section{REVISTA ELETRÔNICA \\ DA GRADUAÇÃO/PÓS-GRADUAÇÃO EM EDUCAÇÃO UFG/REJ}

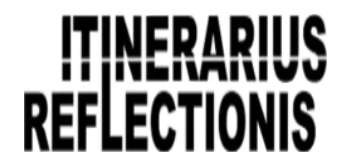

ISSN. 1807-9342

Volume 14, N. 2, 2018

Nesse cenário foi aprovada a Lei de Diretrizes e Bases da Educação Nacional LDB, Lei $\mathrm{n}^{\circ}$ 9.394/96, promulgada em 20 de dezembro de 1996. A LDB reitera a educação como dever da família e do Estado, uma vez que isso já havia sido estabelecido na Constituição Federal de 1988. Vale observar que a LDB foi aprovada praticamente simultaneamente ao FUNDEF, sendo necessário destacar ainda a facilidade encontrada pelo Poder Executivo na aprovação dessas leis, bem como da Emenda Constitucional no 14/1996 (ROSSINHOLI, 2008). Para Pinto (2002), essa lei pouco acrescentou em relação à situação inicial de financiamento da educação.

O FUNDEF caracterizou-se como um fundo de âmbito estadual de natureza contábil, formado por recursos das três esferas de governo, Federal, Estadual e Municipal. Sua criação pela Emenda Constitucional no 14/1996 e regulamentação pela Lei 9.424/96 vinculou recursos para o ensino fundamental, aumentou o percentual de $50 \%$ para $60 \%$ dos recursos dos impostos e transferências de Estados, Distrito Federal e Municípios neste nível de ensino. Por outro lado, reduziu a participação da União para $30 \%$, conforme parágrafo $6^{\circ}$ do Artigo 60 do Ato das Disposições Constitucionais Transitórias - ADCT da Constituição Federal de 1988 (ROSSINHOLI, 2008).

Segundo o artigo 60, $\S 2^{\circ}$, do Ato das Disposições Constitucionais Transitórias, as receitas do FUNDEF são compostas por $15 \%$ dos seguintes impostos e transferências: Imposto sobre Circulação de Mercadorias e Serviços (ICMS); fundos de Participação dos Estados (FPE) e de Participação dos Municípios (FPM); Imposto sobre Produtos Industrializados, proporcional às exportações (IPI-Exp) e ressarcimento pela desoneração das exportações, de que trata a Lei Complementar n 87/96 (Lei Kandir) (BRASIL, 1988).

O FUNDEF inclui recursos federais destinados aos estados cujo gasto aluno/ano, fica abaixo de um valor mínimo preestabelecido que, por sua vez, é estipulado anualmente por decreto presidencial e deve levar em conta os resultados do censo escolar e de estimações das receitas tributárias e de transferências destinadas à educação, incluindo recursos no âmbito dos governos estadual e municipal. O valor necessário para que as unidades federadas mais carentes atinjam o gasto anual mínimo por aluno é repassado pelo governo federal a fundo perdido (NEGRI, 1997). Importante ressaltar que tal gasto mínimo não necessariamente corresponde ao valor efetivamente 


\section{REVISTA ELETRÔNICA \\ DA GRADUAÇÃO/PÓS-GRADUAÇÃO EM EDUCAÇÃO UFG/REJ}

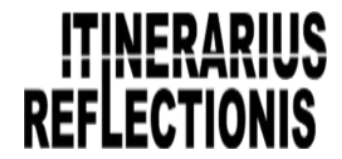

ISSN. 1807-9342

Volume 14, N. 2, 2018

aplicado por aluno na educação pública fundamental, podendo representar um valor potencial ou mínimo, dependendo da disponibilidade de receitas em cada estado.

A estrutura de financiamento do FUNDEF prevaleceu até 20 de dezembro de 2006, quando foi então editada a Emenda Constitucional $n^{\circ}$ 53, alterando vários artigos que tratam da educação (BRASIL, 2006) e criando o Fundo de Manutenção e Desenvolvimento da Educação Básica e de Valorização dos Profissionais da Educação (FUNDEB) no âmbito de cada Estado e do Distrito Federal. Substitui-se, assim, o FUNDEF, instituído em 1996 e em vigor no período de 1998 a 2006 (CASTRO, 2010).

Segundo Rossinholi (2008), é necessário observar que no contexto de transformações vivenciadas na legislação brasileira, na participação das esferas nacionais na educação, na busca de cada esfera pelo aumento da sua participação no total tributado, na grande mudança e consolidação, ao menos tributária do federalismo no Brasil a partir da Constituição Federal de 1988, na desigualdade regional e, claro, na melhoria da educação no Brasil, é que devemos analisar o contexto da criação do FUNDEF e da sua transformação no FUNDEB.

No Brasil, o regulamento do FUNDEB, em 2007, ampliou a cobertura do fundo e estabeleceu uma estrutura de financiamento que detalha o conjunto de verbas que o sustenta e os percentuais a serem investidos em cada nível educacional. Os recursos são distribuídos proporcionalmente ao número de matrículas de cada Estado e se pondera o custo estimado do aluno em cada região, nível, grau e modalidade de ensino. A cifra é determinada pelo Poder Executivo federal para cada exercício fiscal com base no custo real de um estudante dos primeiros anos do nível primário em área urbana. Fixa, além disso, um gasto mínimo por aluno que deve ser alcançado em todo o país. Cabe assinalar que, até meados dos anos 1990, não havia uma delimitação clara das responsabilidades dos níveis estadual e municipal em relação ao financiamento educativo (MORDUCHOWIEZ e ARANGO, 2010).

\section{INOVAÇÕES TRAZIDAS COM A CRIAÇÃO DO FUNDEF/ FUNDEB}

Um dos principais aspectos positivos aponta para ganhos no ensino fundamental promovidos pela aprovação do FUNDEF, levando à quase universalização deste nível de ensino. Outros ganhos foram observados entre aqueles municípios das regiões mais 


\section{REVISTA ELETRÔNICA \\ DA GRADUAÇÃO/PÓS-GRADUAÇÃO EM EDUCAÇÃO UFG/REJ}

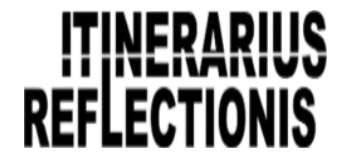

ISSN. 1807-9342

Volume 14, N. 2, 2018

pobres, representando para os municípios do Nordeste, por exemplo, ganho de cerca de $85 \%$ em relação à contribuição realizada.

Em 1998, ano de implantação obrigatória do FUNDEF, 2.159 municípios trabalhariam com um valor por aluno/ano abaixo do limite mínimo estabelecido nacionalmente (R\$ 315,00), sendo que mais de 900 municípios trabalhariam com um valor abaixo de R \$ 150,00 caso o FUNDEF não existisse. Com relação à remuneração do magistério, a região Nordeste teve o maior incremento de salário, alcançando no período de 19972001 um aumento de $60 \%$ (BRASIL, 2006).

A maior inovação do FUNDEF consistiu na mudança da estrutura de financiamento do ensino fundamental no país, pela subvinculação de uma parcela dos recursos a esse nível de ensino, com distribuição de recursos realizada automaticamente, promovendo a partilha de responsabilidades entre o governo estadual e os governos municipais. As receitas e despesas correspondentes, por sua vez, deverão estar previstas no orçamento e na execução, contabilizada de forma específica. Dos recursos do FUNDEF, parcela nunca inferior a $60 \%$, deverá ser destinada ao pagamento dos professores do ensino fundamental em efetivo exercício no magistério podendo uma parte desses recursos ser aplicada na capacitação de professores leigos (BORGES; SOUZA, 2004).

Quanto mais alunos matriculados no ensino fundamental (de $1^{\circ}$ ao $9^{\circ}$ anos), mais recursos podem ser sacados do fundo. Por isso, os municípios dão prioridade ao ensino fundamental e estimulam as matrículas neste nível de ensino. Segundo dados da Secretaria de Educação Básica, na educação infantil apenas 18,5\% da população até seis anos é atendida nas escolas públicas municipais e estaduais atualmente; no ensino fundamental, 97\% das crianças de 7 a 14 anos estão matriculadas e, no ensino médio, cerca de $40 \%$ dos jovens de 15 a 17 anos são atendidos (MATTAR, 2014).

Outro aspecto importante implementado com o FUNDEF é a criação de mecanismos de incentivo à participação da sociedade civil e controle social, por meio da fiscalização dos recursos destinados à educação. O artigo $4^{\circ}$ da Lei n ${ }^{\circ}$ 9.424/96 determina a instituição nos âmbitos federal, estaduais e municipais de Conselho de Acompanhamento e Controle Social do FUNDEF. A criação de conselhos contribui para a gestão democrática de políticas públicas, sendo o fortalecimento do controle 


\section{REVISTA ELETRÔNICA \\ DA GRADUAÇÃO/PÓS-GRADUAÇÃO EM EDUCAÇÃO UFG/REJ}

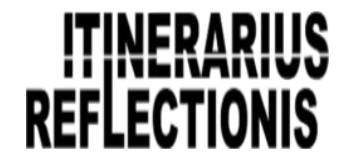

ISSN. 1807-9342

Volume 14, N. 2, 2018

social a melhor maneira de fiscalizar as ações da administração pública. Além do papel dos conselhos, a existência de uma conta única e específica para os recursos do fundo tem o intuito de dar maior visibilidade à gestão das verbas vinculadas à educação, facilitando a fiscalização, o acesso às informações sobre a utilização das verbas do Fundo e a elaboração de denúncias aos órgãos competentes sobre eventuais irregularidades na utilização dos recursos do FUNDEF (VAZQUEZ, 2005).

Por ser um recurso vinculado, as transferências da União para o FUNDEB têm autonomia subnacional limitada. Os recursos aplicados pelo governo federal (bem como as contrapartidas municipais e estaduais) são preestabelecidos de forma rígida. Um ponto forte do sistema é que ele favorece o aumento da accountability (termo da língua inglesa que pode ser traduzido para o português como responsabilidade com ética. Também pode ser traduzido como controle, fiscalização, responsabilização ou prestação de contas), pois a vinculação da expansão dos montantes recebidos à melhoria do desempenho dos alunos, tanto em termos de notas quanto de repetência, fornece à comunidade um dispositivo prático e imediato de conferência de resultados e de responsabilização das autoridades municipais e estaduais por esses resultados. Esse sistema, por possuir regras claras e mecanismos de transferências ligados a informações públicas, como o resultado da Prova Brasil e as estatísticas de reprovação, reduz a vulnerabilidade do sistema a pressões e influências políticas nos critérios de distribuição (MENDES, MIRANDA e COSIO, 2008).

\section{LIMITAÇÕES DO FUNDEF/ FUNDEB ENQUANTO INSTRUMENTO DE REDUÇÃO DAS DESIGUALDADES REGIONAIS NO SISTEMA EDUCACIONAL BRASILEIRO}

Dentre as limitações observadas no FUNDEF/FUNDEB podemos destacar: indução à municipalização, desresponsabilização da União e incapacidade para promover a redução das desigualdades regionais no financiamento do ensino fundamental (PINTO, 2006; SENA, 2006), fato verificado pela pequena participação da União: em 1998, era de 3,29\% do montante total dos recursos, além de uma redução percentual da complementação que, no ano de 2005, foi de apenas $1,14 \%$ (ROSSINHOLI, 2008). Há também a diminuição da atenção para outros níveis de 


\section{REVISTA ELETRÔNICA \\ DA GRADUAÇÃO/PÓS-GRADUAÇÃO EM EDUCAÇÃO UFG/REJ}

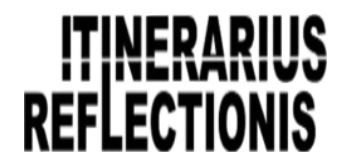

ISSN. 1807-9342

Volume 14, N. 2, 2018

ensino, além de problemas na fiscalização e acompanhamento do FUNDEF (GUIMARÃES, 2004; RODRIGUES, 2001). Outra limitação observada é o estabelecimento do valor mínimo do custo-aluno abaixo do previsto em legislação e do necessário para garantir um ensino de qualidade (CALLEGARI, 2002; VASQUEZ, 2005).

A principal fragilidade do FUNDEF tem sido reiteradamente apontada pela maioria dos especialistas como decorrência do fato de o Fundo financiar exclusivamente o ensino fundamental em detrimento da educação infantil e do ensino médio, etapas que integram a educação básica.

Nesse contexto, Abrucio (2010) afirma que o sucesso desses fundos federativos não pode esconder os problemas que ainda persistem no plano intergovernamental. Em primeiro lugar, eles conseguiram dar mais recursos aos governos que se responsabilizam pela política, mas mexeram pouco com as desigualdades regionais que marcam a federação brasileira. Para tanto, seria necessário que a União não só complementasse o dinheiro que falta para chegar à meta básica, mas que também fizesse política redistributiva. Caso contrário, a equalização se dá num patamar mínimo, e as redes dos estados mais ricos tendem a ter uma diferença substancial de condições em relação aos demais. Ressalte-se ainda que os governos subnacionais queixam-se que nem a atividade supletiva mínima vem sendo exercida pelo governo federal (ABRUCIO, 2010).

Similarmente, Mattar (2014) aponta que a priorização do ensino fundamental causa uma distorção entre as verbas destinadas a este nível e as verbas destinadas aos demais níveis, educação infantil (creche e pré-escola) e ensino médio (etapa final da educação básica). A explicação é simples: o FUNDEF é um fundo estadual, dividido entre os municípios de acordo com o número de alunos matriculados em cada um deles. Anualmente, é feito um cálculo de custo por aluno. Cada município saca do FUNDEF (que recebe as receitas de determinados impostos recolhidos pelo estado) o valor equivalente à seguinte equação: custo por cada aluno multiplicado pelo número total de alunos matriculados (MATTAR, 2014).

$\mathrm{Na}$ vigência do Governo Luiz Inácio Lula da Silva, o relatório que avaliou o FUNDEF, no período compreendido entre 1997 e 2002, explicitou a todos que as regras de financiamento definidas na $\mathrm{CF} / 1988$ revelaram - 


\section{REVISTA ELETRÔNICA \\ DA GRADUAÇÃO/PÓS-GRADUAÇÃO EM EDUCAÇÃO UFG/REJ}

\section{TTEERPUS REFLECTIONIS}

ISSN. 1807-9342

Volume 14, N. 2, 2018

se limitadas para produzir as mudanças estruturais e qualitativas necessárias ao ensino fundamental, já que a legislação não contemplava mecanismos reguladores que fossem para assegurar efetiva aplicação das verbas destinadas à educação e, além disso, pela ausência de uma definição clara das responsabilidades a serem assumidas pelos estados e municípios no tocante à demanda pelos diferentes níveis de educação (BRASIL, 2006).

Davies $(1999,28)$ questionou o valor anual mínimo fixado pelo presidente da República, para o ano de 1998. Segundo o autor, se o parágrafo $1^{\circ}$ do Art. $6^{\circ}$ da lei do FUNDEF fosse cumprido, que prevê ser o valor mínimo anual nunca inferior "à razão entre a previsão da receita total para o Fundo e a matrícula total do ensino fundamental do ano anterior, acrescida do total estimado de novas matrículas", teria maior efetividade. As médias regionais de recursos por alunos são inversas àquelas compatíveis com a verdadeira busca da equalização, as médias por aluno das regiões Sul e Sudeste são maiores que as médias das demais regiões, demonstrando uma concentração dos recursos educacionais nas regiões mais desenvolvidas. É marcante o fato de que a região Nordeste recebe, por aluno, apenas $\mathrm{R} \$ 492,00$ em média, o que significa um terço a menos dos recursos per capita que a região Sudeste (MENDES, MIRANDA e COSIO, 2008).

Para Mendes, Miranda e Cosio (2008), a distribuição regional dos recursos para educação tem sido, na prática, menos distributiva que aquela associada aos fundos de participação (FPM e FPE), a despeito de sua intenção equalizadora. Segundo esses autores, as regiões Norte e Nordeste receberam, em 2006, uma proporção menor do FUNDEF em relação ao total nacionalmente distribuído do que seus coeficientes nos fundos de participação, enquanto que situação oposta se verifica com relação às regiões Sul e Sudeste. A região Centro-Oeste é um caso intermediário, no qual os dois coeficientes são aproximadamente equivalentes.

Esse caráter menos redistributivo associado aos gastos com educação tende a agravar o problema regional, já que na economia moderna a educação tem sido reconhecida como uma "mola mestra" do desenvolvimento. Se as regiões mais desenvolvidas do País recebem proporções maiores dos gastos com educação, isso pode significar a ausência de um mecanismo de convergência econômica entre as regiões brasileiras e, como veremos, adiante, esse padrão também se 


\section{REVISTA ELETRÔNICA \\ DA GRADUAÇÃO/PÓS-GRADUAÇÃO EM EDUCAÇÃO UFG/REJ}

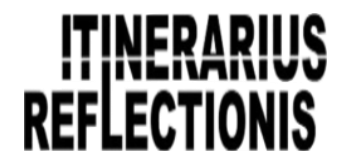

ISSN. 1807-9342

Volume 14, N. 2, 2018

repete quando as distribuições per capita são consideradas (MENDES, MIRANDA e COSIO, 2008, p. 80).

Diversos autores mostram que os critérios de distribuição dessas transferências são inadequados e geram distorções e perda de eficiência. Mendes (2001), por exemplo, mostra que os grandes beneficiários do sistema de partilha são os pequenos municípios, onde é limitado o rol de serviços públicos que se pode ofertar à sociedade, devido à inexistência de economias de escala. Rezende (1998), por sua vez, aponta que as grandes cidades são as grandes prejudicadas na divisão dos recursos, não dispondo de condições para financiar investimentos de alto custo necessários para lidar com problemas gerados em grandes aglomerações urbanas. Andrade, Santos e Costa (2000) apontam as cidades médias, em especial as nordestinas, como outro grupo perdedor no sistema vigente de partilha fiscal.

Embora o FUNDEF/FUNDEB garanta um gasto mínimo por aluno, ele não é capaz de fazer com que o gasto por estudante nas regiões menos desenvolvidas cresça de forma a alcançar o montante despendido pelas regiões Sul e Sudeste, tendo em vista que essas regiões encontram-se em um patamar de gasto muito acima do mínimo legal estabelecido. Esse padrão certamente não favorece a redução dos hiatos fiscais nas diversas localidades brasileiras, posto que as regiões mais pobres são aquelas com maior carência educacional e, portanto, maior demanda por esse serviço, cujos recursos estão sendo apropriados, prioritariamente, pelas regiões mais ricas (MENDES, MIRANDA e COSIO, 2008).

Se a lei do FUNDEF fosse cumprida, um número maior de estados receberia recursos federais, aumentando o seu gasto por aluno e os que efetivamente receberam, receberiam mais por aluno. A consequência é que o gasto/aluno médio nacional seria aumentado, reduzindo mais fortemente a desigualdade (ABRUCIO, 2010).

Apesar de o fundo permitir comparações objetivas entre as produtividades das unidades, favorecendo dessa forma a análise do gasto público, a única exceção do sistema é que pode induzir os estados e municípios receptores à leniência tributária, visto que o Governo Central é obrigado a complementar recurso sempre que a arrecadação local mostrar-se insuficiente para financiar um gasto mínimo por aluno. Isso pode induzir o relaxamento na arrecadação, como forma de credenciar o estado a receber transferências federais. Todavia, esse efeito é contrabalançado pelo fato de que 


\section{REVISTA ELETRÔNICA \\ DA GRADUAÇÃO/PÓS-GRADUAÇÃO EM EDUCAÇÃO UFG/REJ}

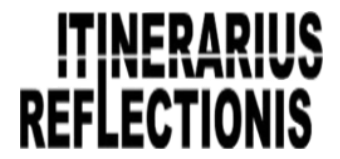

ISSN. 1807-9342

Volume 14, N. 2, 2018

o estado necessita de recursos fiscais próprios para custear todas as demais despesas que não contam com subsídio federal (MENDES, MIRANDA e COSIO, 2008).

Por fim, cabe esclarecer que a valorização dos profissionais da educação, principalmente daqueles que atuam com a base da educação, ou seja, na educação básica, poderia estar em outros patamares se os governos anteriores ao ano de 2003 tivessem tido maior responsabilidade com o FUNDEF/FUNDEB, o que ressoaria, certamente, na qualidade educacional tão esperada pela população brasileira. Em consonância com Moreira (2015), entendemos que somente com o reconhecimento dos professores e os investimentos adequados na educação, é possível mudar algumas marcas da histórica desvalorização do magistério em nosso país, o que reflete, certamente, na qualidade do ensino ofertado.

\section{CONSIDERAÇÕES FINAIS}

A educação assume um papel central para fomentar novas formas de organização social e de contribuir com a possibilidade de desenvolvimento e democracia no país. Cabe à escola a tarefa de possibilitar uma formação cidadã de sujeitos críticos e participativos, o que perpassa, necessariamente pela valorização dos profissionais que atuam, principalmente, na educação básica (SANDES e MOREIRA, 2018). Porém, o baixo comprometimento do governo federal com a educação básica, alicerce de todo o sistema educacional brasileiro, e as desigualdades regionais existentes no Brasil são problemas que repercutem no desenvolvimento econômico e social do país.

Os bons resultados do FUNDEF ficaram evidentes uma vez que o governo Lula manteve boa parte de suas diretrizes na criação do FUNDEB (Fundo de Manutenção e Desenvolvimento da Educação Básica e de Valorização dos Profissionais da Educação), cujo objetivo é levar a mesma universalização ao ensino médio e à educação infantil. Porém, a maneira como ocorreu a mudança já expressou uma crítica federativa ao modelo decisório do período FHC. Muitos estados e municípios sentiram que não participaram da formulação do FUNDEF e quiseram ter uma participação maior. Prefeitos, governadores e, com destaque especial, os fóruns federativos existentes na educação, o Consed (Conselho Nacional dos Secretários Estaduais de Educação) e a 


\section{REVISTA ELETRÔNICA \\ DA GRADUAÇÃO/PÓS-GRADUAÇÃO EM EDUCAÇÃO UFG/REJ}

\section{ITEERPUW REFLECTIONIS}

ISSN. 1807-9342

Volume 14, N. 2, 2018

Undime (União Nacional dos Dirigentes Municipais de Educação), foram fortemente envolvidos em todo o processo. $\mathrm{O}$ fato é que a ação coordenadora da União pela via do FUNDEF, mesmo que vista como uma ação centralizadora que ouviu pouco os governos subnacionais, gerou maior consciência intergovernamental (ABRUCIO, 2010).

Constata-se que o governo federal tem um maior comprometimento com o ensino superior e as esferas estadual e municipal com os anos iniciais. Essa situação não seria ruim caso a desigualdade regional fosse menor e houvesse mais recursos nestas esferas destinados à educação. Entretanto, na presente realidade onde a arrecadação de impostos se apresenta concentrada em alguns Estados, torna-se bastante difícil desenvolver uma educação de qualidade com equidade sem recursos federais de forma homogênea por todo o território.

Apesar do FUNDEF, precursor do atual FUNDEB, ter levado ao aumento de matrículas, apresentou, dentre outros, os seguintes problemas: o baixo comprometimento da União com o ensino fundamental, o baixo valor mínimo estabelecido para o qual haveria complementação da União, a rápida municipalização sem um preparo por parte dos municípios, a exclusão da educação infantil e do ensino médio, a manutenção de valores significativamente diferentes entre os estados federados e as dificuldades no acompanhamento e fiscalização dos recursos transferidos através do Fundo. Nesse sentido a necessidade de aprovação do FUNDEB ocorreu em função de diversos fatores, tais como a aproximação do final do período para o qual o FUNDEF havia sido aprovado, da pressão pelo maior envolvimento da União no financiamento da Educação Básica e pela necessidade de correção dos problemas apresentados com a criação do referido fundo, principalmente em relação à educação infantil.

Outro ponto importante seria tornar as transferências realmente equalizadoras, pois os gastos com educação podem propiciar uma tendência de equalização de renda e desenvolvimento humano em longo prazo, uma vez que o aumento do nível e da qualidade escolar das regiões menos prósperas é poderoso fator de desenvolvimento. Assim sendo, a reestruturação dessas transferências vinculadas, de modo a equalizar, ou mesmo tornar maior a disponibilidade de recursos nas regiões mais pobres se faz necessária. Deve-se, contudo, atentar para o fato de que transferências equalizadoras podem gerar incentivos inapropriados à gestão fiscal dos entes federativos. 


\section{REVISTA ELETRÔNICA \\ DA GRADUAÇÃO/PÓS-GRADUAÇÃO EM EDUCAÇÃO UFG/REJ}

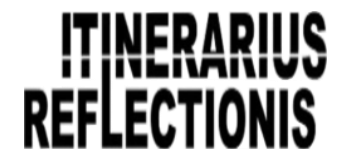

ISSN. 1807-9342

Volume 14, N. 2, 2018

Apesar das constantes afirmações sobre a necessidade de investimentos em educação, estes não têm ocorrido de forma a compensar o déficit existente nesta área. Um país com o nível de desigualdades regionais como o Brasil dependerá obrigatoriamente, de políticas públicas com verbas originadas de impostos federais bem utilizadas para tentar superar esse problema tanto na educação como nos demais setores.

Vale ressaltar que elevar a carga tributária brasileira não resolverá os problemas no setor educacional, pois esta já apresenta níveis extremamente elevados se comparada com a de países com mesmo nível de desenvolvimento do Brasil. É necessária a definição da participação da União como promotora da redução das desigualdades regionais, sendo necessário também analisarmos a relação entre estados e municípios, não podendo a educação ser discutida apenas como uma busca por recursos, em que a esfera que tiver mais alunos terá mais recursos.

Por fim, entende-se que a aplicação adequada dos recursos públicos destinados à educação por meio do FUNDEB, pode ser melhor para a educação no Brasil, mas fica presente a necessidade de mobilização para a destinação de mais recursos que sejam bem utilizados neste setor. São necessárias mais pesquisas que promovam o estudo da participação da União no período para o qual o FUNDEB foi aprovado, além de estudos sobre o acompanhamento da correção dos valores mínimos por aluno, índices de participação das etapas de educação, estabelecimento e atualização do piso salarial e o efetivo funcionamento dos Conselhos de Acompanhamento e Controle Social e da Comissão Intergovernamental de Financiamento para a Educação Básica de Qualidade com equidade.

\section{REFERÊNCIAS}

ABRUCIO, F. L. A Dinâmica Federativa da Educação Brasileira: diagnóstico e propostas de aperfeiçoamento. In: OLIVEIRA, R. P. de; SANTANA, W. (Org.).

Educação e federalismo no Brasil: combater as desigualdades, garantir a diversidade. Brasília: UNESCO, 2010.

AFONSO J. R. R.; SOARES, J. M. S.; CASTRO, K. P de. Avaliação da estrutura e do desempenho do sistema tributário Brasileiro. BID, n. 40, Brasília, 2013.

BORGES, V. O; SOUZA, G. M. Manual de Orientação do FUNDEF. Brasília: Secretaria de Educação Fundamental, 2004. 


\section{REVISTA ELETRÔNICA \\ DA GRADUAÇÃO/PÓS-GRADUAÇÃO EM EDUCAÇÃO UFG/REJ}

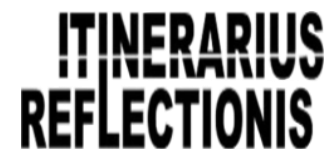

ISSN. 1807-9342

Volume 14, N. 2, 2018

BRASIL. Lei de Diretrizes e Bases da Educação. Lei № 9.394, de 20 de dezembro de 1996. Estabelece as diretrizes e bases da educação nacional. Brasília, 1996.

BRASIL. Constituição da República Federativa do Brasil. Brasília: Senado Federal, 1988. Disponível em:

<http://www.planalto.gov.br/ccivil_03/constituicao/constituicao.htm.>. Acesso em: 05 jul. 2018.

BRASIL. FUNDEF: Relatório sintético 1998/2002. Brasília: MEC, 2006.

CALLEGARI, C. O FUNDEF e a municipalização do ensino fundamental no

Estado de São Paulo. São Paulo: Aquariana, 2002.

CASTRO, J. A. Financiamento da Educação Pública no Brasil: evolução dos gastos. In: OLIVEIRA, Romualdo Portela de; SANTANA, Wagner (Org.). Educação e federalismo no Brasil: combater as desigualdades, garantir a diversidade. Brasília: UNESCO, 2010.

DAVIES, N. O FUNDEF e o Orçamento da Educação: desvendando a caixa preta. Campinas - SP: Autores Associados. 1999.

GUIMARÃES, J. L. Alguns Impactos do Fundef: apontamentos e incertezas após sua implantação. In: MARTINS, A. M.; OLIVEIRA, C.; BUENO, M. S. S. (Org.).

Descentralização do estado e municipalização do ensino: problemas e perspectivas. Rio de Janeiro: DP\&A, 2004.

MATTAR, M. E. Brasil: Sociedade civil influi nos rumos da legislação sobre financiamento da educação. 2014. Disponível em:

http://www.educacionenvalores.org/Brasil-Sociedade-civil-influi-nos.

MENDES, M. Descentralização do ensino fundamental: Avaliação de Resultados do Fundef. Revista de Planejamento e Políticas Públicas, n. 24, 2001.

MENDES, M.; MIRANDA, R. B.; COSIO, F. B. Transferências

Intergovernamentais no Brasil: diagnóstico e proposta de reforma. Textos Para Discussão 40. Consultoria Legislativa do Senado Federal. Brasília: Conleg, 2008.

MORDUCHOWIEZ, A.; ARANGO, A. Desenho Institucional e Articulação do Federalismo Educativo: experiências internacionais. In: OLIVEIRA, R. P. de; SANTANA, W. (Org.). Educação e federalismo no Brasil: combater as desigualdades, garantir a diversidade. Brasília: UNESCO, 2010.

MOREIRA, G. E. A Educação Matemática Inclusiva no contexto da Pátria Educadora e do novo PNE: Reflexões no âmbito do GD7. Educação Matemática Pesquisa, v. 17, n. 3, São Paulo, 2015.

NEGRI, B. O Fundo de Manutenção e Desenvolvimento do Ensino Fundamental e de Valorização do Magistério. Brasília: Inep, 1997.

PINTO, J. M. R. Uma proposta de custo-aluno-qualidade na educação básica. Revista Brasileira de Política e Administração da Educação, v. 22, n. 2, Brasília, jul/dez., 2006.

. Financiamento da educação no Brasil: um balanço do governo FHC (1995-

2002). Educação e Sociedade, v. 23, n. 80, Campinas, set., 2002. 


\section{REVISTA ELETRÔNICA \\ DA GRADUAÇÃO/PÓS-GRADUAÇÃO EM EDUCAÇÃO UFG/REJ}

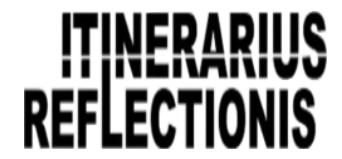

ISSN. 1807-9342

Volume 14, N. 2, 2018

RODRIGUES, V. Financiamento da educação e políticas públicas: o FUNDEF e a política de descentralização. Cadernos Cedes, vol. 21, n. 55, Campinas, nov., 2001.

ROSSINHOLI, M. Política de Financiamento da Educação Básica no Brasil: Do Fundef ao Fundeb. Tese (Doutorado em Educação). Programa de Pós-Graduação em Educação da UNIMEP. Piracicaba-SP: UNIMEP, 2008.

SANDES, J. P.; MOREIRA, G. E. Educação Matemática e a Formação de Professores para uma prática docente significativa. Revista @ mbienteeducação, v. 11, 2018.

SANTOS, A.; COSTA, L; ANDRADE, T. Federalismo no Brasil: análise da descentralização financeira da perspectiva das cidades médias. Brasília: IPEA, 2000.

SOBREIRA, R.; CAMPOS, B. C. Investimento público em educação fundamental e a qualidade do ensino: uma avaliação regional dos resultados do Fundef. Revista de Administração Pública, v. 42, n. 2, Rio de Janeiro, mar./abr., 2008.

SENA, P. Financiamento da educação básica: critérios conceitos e diretrizes. In: LIMA, M. J. R.; DIDONET, V. (Org.). FUNDEB: avanços na universalização da educação básica. Brasília: INEP, 2006.

SOUZA, P. R. Introdução. In: BRASIL. Balanço do primeiro ano do Fundef. Brasília: Ministério da Educação, 1998.

VAZQUES, D. A. Desequilíbrios regionais no financiamento da educação: a política nacional de equidade do FUNDEF. Revista de Sociologia e Política, n. 24, jun., 2005. 